\title{
Ethnic differences and socio-demographic predictors of illness perceptions, self-management, and metabolic control of type 2 diabetes
}

This article was published in the following Dove Press journal:

International Journal of General Medicine

29 July 2013

Number of times this article has been viewed

\author{
Abdul-Razak Abubakari ${ }^{1}$ \\ Martyn C Jones ${ }^{2}$ \\ William Lauder ${ }^{3}$ \\ Alison Kirk ${ }^{4}$ \\ John Anderson ${ }^{5}$ \\ Devasenan Devendra ${ }^{6}$ \\ Ebrahim K Naderali \\ 'School of Health Sciences, Liverpool \\ Hope University, Hope Park, \\ Liverpool, ${ }^{2}$ School of Nursing and \\ Midwifery, University of Dundee, \\ Dundee, ${ }^{3}$ School of Nursing and \\ Midwifery and Health, University \\ of Stirling, Stirling, ${ }^{4}$ Department \\ of Sport, Culture and the Arts, \\ University of Strathclyde, Glasgow, \\ ${ }^{5}$ Homerton University Hospital NHS \\ Trust, Homerton Row, London, \\ ${ }^{6}$ West Hertfordshire Hosptials NHS \\ Trust, Watford, UK
}

Objectives: This study investigated ethnic differences in diabetes-specific knowledge, illness perceptions, self-management, and metabolic control among black-African, black-Caribbean, and white-British populations with type 2 diabetes. The study also examined associations between demographic/disease characteristics and diabetes-specific knowledge, illness perceptions, selfmanagement, and metabolic control in each of the three ethnic groups.

Design: Cross-sectional

Setting: Diabetes/retinal screening clinics in Hackney and Brent, London.

Methods: Black-African, black-Caribbean and white-British populations with type 2 diabetes were asked to participate. Questionnaires measuring demographic/disease characteristics, diabetes-specific knowledge, self-management, and illness perceptions were used for data collection. Data for glycated hemoglobin $\left(\mathrm{HbA}_{1 \mathrm{c}}\right)$ and microvascular complications were obtained from medical records. Ethnic differences in diabetes-related measures were estimated using analysis of variance/covariance. Multiple regression techniques were used to determine relationships between demographic/disease characteristics and measured diabetes-related outcomes.

Results: Three hundred and fifty-nine patients participated in the study. White-British participants had high diabetes-specific knowledge compared to their black-African and black-Caribbean counterparts. Black-Africans reported better adherence to self-management recommendations than the other ethnic groups. Compared to the white-British patients, blackAfrican and black-Caribbean participants perceived diabetes as a benign condition that could be cured. Educational status and treatment category were determinants of diabetes-specific knowledge in all three ethnic groups. However, different demographic/disease characteristics predicted adherence to self-management recommendations in each ethnic group.

Conclusion: Clearly, there is disease (diabetes) knowledge-perception variation between different ethnic groups in the UK which may partly influence overall disease outcome. It is plausible to recommend screening, identifying, and dispelling misconceptions about diabetes among ethnic minority patients by health care professionals as well as emphasizing the importance of self-management in managing chronic diseases such as diabetes.

Keywords: black-African, black-Caribbean, white-British, diabetes, illness perceptions, self-management

\section{Introduction}

Diabetes has become a global epidemic with over 371 million people affected worldwide. ${ }^{1}$ As a result of the sustained hyperglycemia that often characterizes the condition, people with diabetes have a high risk of developing microvascular and macrovascular complications in the long term. ${ }^{2}$ These complications include retinopathy, neuropathy, nephropathy, cerebrovascular, and cardiovascular diseases.
Correspondence: Abdul-Razak Abubakari School of Health Sciences, Liverpool Hope University, Hope Park, Liverpool, UK

Email abubakr@hope.ac.uk 
In fact, diabetes is the second biggest cause of cardiovascular disease in the UK and a major cause of death and disability in most developed countries. ${ }^{3,4}$

To avoid or minimize the risk of diabetes complications, patients are encouraged to play an active role in the day-today management of their condition, a phenomenon referred to as self-management. ${ }^{5}$ The Recommended Diabetes SelfManagement (DSM) activities include dietary planning, regular exercise, blood glucose monitoring, and where applicable, appropriate use of oral-hypoglycemic or insulin medication. ${ }^{6}$ Patients need to self-regulate if they are to successfully integrate DSM activities into their daily routines. The required adjustments in daily routines may be considerable for many patients. Thus, adherence to DSM recommendations may be influenced by patients' social, cultural, and psychological experiences. ${ }^{7}$ Moreover, self-management is a complex phenomenon and patients need various skills to optimally engage in it. Some of the skills required include some level of health literacy and knowledge about the disease, problemsolving, planning, and decision-making skills.

Depending on the country, time of classification (eg, census year) or route of migration (eg, directly from Africa or via the Caribbean), people of African ancestry are identified by different terminologies in various epidemiological literature. ${ }^{8}$ For example, some of the more recent terminologies used to describe African-origin populations include black-African, black-Caribbean, or African-Caribbean in the UK and African-Americans in the US.

Irrespective of their location, African-origin populations have a higher risk of developing diabetes and its microvascular complications compared to their European-origin counterparts. For example, compared to the general populations of the US, UK, or Australia, the prevalence of diabetes is higher among African-origin populations. ${ }^{9-11}$ African-origin populations also have higher rates of diabetes microvascular complications, including diabetic nephropathy. ${ }^{12,13}$

The ethnic differences in the prevalence of diabetes may partly be explained by variations in genetic predisposition and/or disparities in the general distribution of behavioral risk factors such as 'unhealthy' dietary practices. Data from the US indicate that African-origin patients have poorer diabetes control outcomes compared to non-Hispanic white Americans. ${ }^{14}$ Nonetheless, it is important to note that the reasons for the variations in the risk of diabetes complications are generally not clear and that variations in diabetesrelated outcomes are not fully explained by self-management behaviors. ${ }^{15}$ In some specific populations (mainly Europeanorigin), the illness perceptions of people with diabetes are found to predict adherence to DSM recommendations or glycemic control. ${ }^{16}$ Investigating ethnic differences in illness perceptions about diabetes may therefore help to explain some of the observed disparities in self-management and metabolic control of diabetes. ${ }^{14,17}$ Thus, this study was designed to answer the following research questions:

1. Do differences exist in diabetes-related knowledge, illness perceptions, self-management, or glycated hemoglobin $\left(\mathrm{HbA}_{1 \mathrm{c}}\right)$ levels between black-Africans, black-Caribbean, and white-British patients?

2. Which demographic/disease characteristics predict diabetes-specific knowledge, self-management, or $\mathrm{HbA}_{1 \mathrm{c}}$ levels in each of the three ethnic groups?

3. Do illness perceptions of people with diabetes in any of the three ethnic groups predict their $\mathrm{HbA}_{1 \mathrm{c}}$ levels or microvascular complication status?

\section{Methods}

\section{Participants and procedures}

People with type 2 diabetes who attended diabetes and retinal screening clinics between February and June 2008 in the London Boroughs of Brent and Hackney were recruited for this study. The two Boroughs have higher proportions of African-origin populations compared to other locations in the UK. ${ }^{18}$ Patients who were adults ( $\geq 18$ years), capable of providing consent, understood and spoke English, and identified their ethnicity as black-African, black-Caribbean, or white-British (in accordance with the UK's 2001 census classification) were eligible to participate. To minimize potential practical, ethical and methodological difficulties, individuals who were unable to speak English; had history of cognitive impairment such as dementia; showed evidence of psychotic disorder; or were suffering from severe pain during their visit to the clinic were excluded, and were not approached to take part. Potential participants were approached consecutively with the invitation letter and participant information sheet about the study. Those who agreed to participate in the study were asked to sign the informed consent form before completing the study questionnaires. Consent forms and study questionnaires were administered to participants who had difficulty reading (eg, some were experiencing blurred vision as they were given eye drops to dilate their pupils as part of the retinal screening procedures and others did not have their reading glasses at hand). Recent data on $\mathrm{HbA}_{1 \mathrm{c}}$ (last 6 months) and microvascular complication status (nephropathy, neuropathy, or retinopathy) for participants were extracted from their medical records held by their registered hospital or general practitioners. Ethical approval 
for the study was granted by the Brent and East London Ethics Committees. The methods for this study have already been reported elsewhere. ${ }^{19}$

\section{Study questionnaires}

A demographic questionnaire was designed to capture data on the age, gender, educational status, ethnicity, duration and type of treatment for diabetes, and number of years resident in the UK. Diabetes-specific knowledge, selfmanagement, and illness perceptions were measured using the brief diabetes knowledge test (DKT), ${ }^{20}$ the summary of diabetes self-care activities (SDSCA), ${ }^{21}$ and the revised illness perceptions (IPQ-R) ${ }^{22}$ questionnaires, respectively. All the three instruments have been validated and found to have acceptable psychometric properties among people with diabetes. ${ }^{20-22}$

The brief DKT is a 23 -item tool with two sub-scales (14-item general and nine-item insulin use sub-scales). The 14-item general knowledge sub-scale was used in this study, as it is suitable for use with type 2 diabetes patients. The questionnaire requires patients to demonstrate from multiple choice questions, what they think are the correct responses about diabetes and its management. The SDSCA has eleven core items which ask patients to indicate how many of the last 7 days they have performed the recommended dietary, exercise, self-monitoring of blood glucose (SMBG), and foot self-management activities. Overall DSM in this study was computed by adding up patients' responses for dietary, exercise, SMBG, and foot self-management. The IPQ-R measures both cognitive and emotional dimensions of illness perceptions using nine sub-scales. The sub-scales include: identity (the symptoms or labels patients associate with their diabetes), timeline-acute/chronic (patients' opinions as to whether their diabetes is a long-term or a short-term condition), timeline-cyclical (patients' perceptions about the stability or changeability of their illness symptoms), consequences (patients' perceptions of the impact the illness has on their lives, their finances, and their close associates), personal control (patients' perceived control over their diabetes), treatment control (patients' perceptions about the effectiveness of their treatment in controlling or curing their diabetes), illness coherence (the consistency of patients' understanding about the illness), emotional representation (patients' mood or feelings about the illness), and cause (patients' beliefs in relation to the possible causes or attributions of their diabetes). Questions for all the subscales (except identity) have five-point Likert-type responses (strongly disagree; disagree; neither agree nor disagree; agree; strongly agree).
The identity subscale has 14 items and each question is scored by a 'yes' or 'no' response. The IPQ-R has recently been found to be acceptably valid and reliable among Africanorigin populations with diabetes. ${ }^{23}$

As demonstrated among Tongans, ${ }^{24}$ 'God's will' was added to the list of 18 causal items contained in the IPQ-R. This addition was informed by our knowledge of the existing literature, which identifies religion as a crucial determinant of how African-origin populations cope with illnesses. ${ }^{25}$ Similar to the brief illness perception questionnaire, ${ }^{26}$ an overall illness perception score (IPS) was computed by reversing participants' scores for personal control, treatment control, and illness coherence perceptions and adding them to the scores for identity, timeline-acute/chronic, consequences, timeline-cyclical, and emotional representation. ${ }^{26}$ The IPS indicates the extent to which patients perceive their illness to be life threatening. Low scores indicate benign perceptions whereas high scores indicate life-threatening perceptions.

\section{Statistical analysis}

Data were entered into SPSS (v 16; SPSS, Inc, Chicago, IL, USA) for statistical analysis. For continuous variables such as age and $\mathrm{HbA}_{1 \mathrm{c}}$, group differences were investigated using analysis of variance (ANOVA). Bonferroni post-hoc procedures were performed to reveal specific differences between individual groups in ANOVA. To minimize the potential for confounding, analysis of covariance (ANCOVA) was used to adjust for statistically significant between-group differences in demographic variables such as age and duration of diabetes. Bivariate correlations were used to investigate relationships between variables. The enter method was used for identifying potential demographic/disease characteristics that predicted various outcomes in multiple regression analysis. In order to reduce losses in degrees of freedom and statistical power, only independent variables that were significantly correlated (or had a correlation coefficient $\geq 0.15$ ) with the appropriate outcome variables were entered into the regression model. ${ }^{27}$ Dummy variables were created for independent ordinal categorical variables with $\leq 4$ states (eg, education status, treatment category), and all comparison options were entered together into the model. In order to investigate ethnic differences in the proportion of participants who attributed their diabetes to individual causal items, responses for each item on the cause subscale were coded into binary categorical variables: agree (strongly agree + agree) and disagree (strongly disagree + disagree). Ethnic differences were then investigated using the chi-square test (see results in Figures 1-3). To minimize 


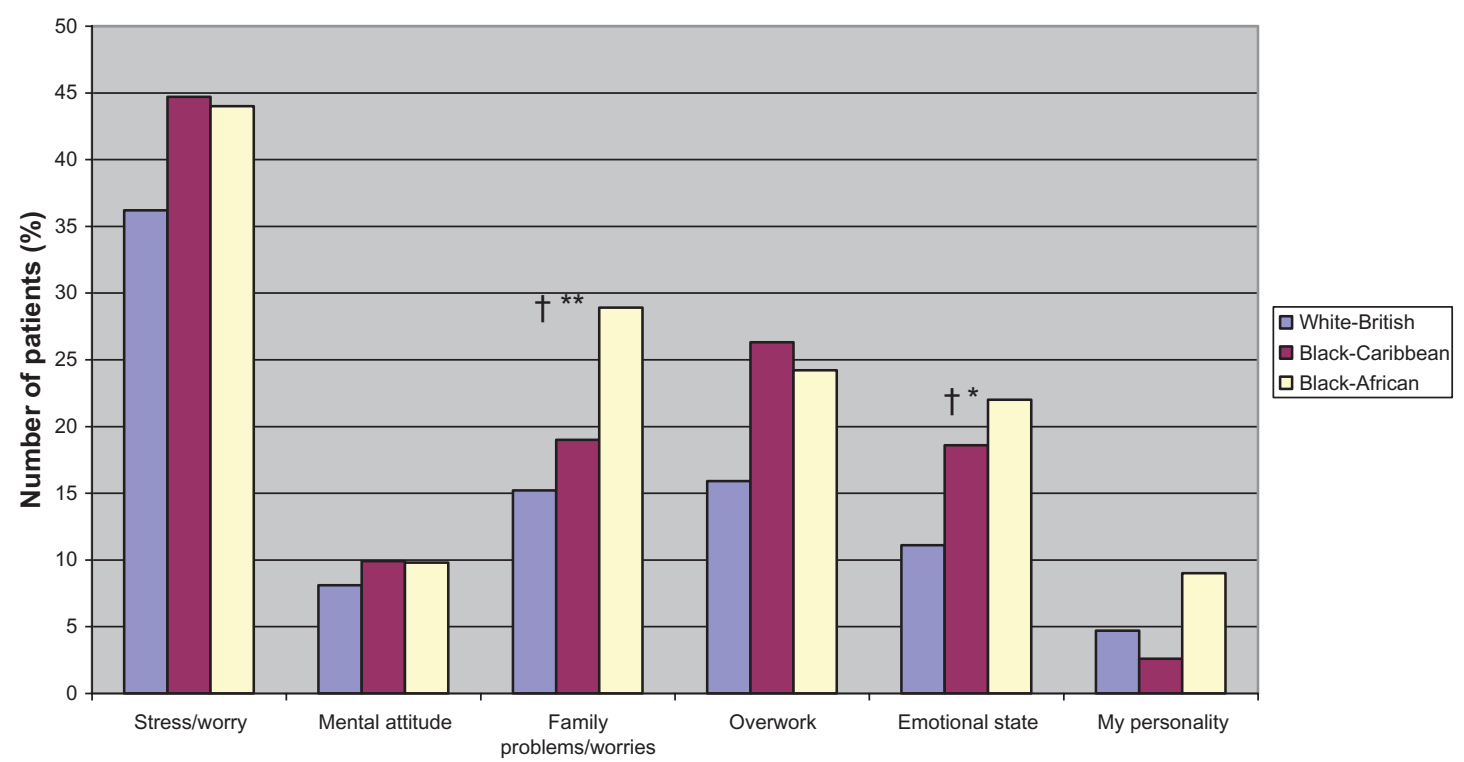

Perceived cause

Figure I Perceived psychological causes of diabetes by ethnicity.

Notes: †Significant linear trend; $* P \leq 0.03$; $* P \leq 0.01$; for significant differences between ethnic groups ( $P$-values are from chi-square tests).

the potential for type 1 errors due to multiple testing, we considered $P$-values $\leq 0.03$ as significant. As reported elsewhere, ${ }^{19}$ the initial determination of sample size based on the effect size of 0.30 for correlations between illness perceptions and self-management, found that a minimum of 82 participants were required for each ethnic group to achieve $80 \%$ power.

\section{Results}

\section{Demographic/disease characteristics}

As shown in Table 1, a number of demographic/disease characteristics differed by ethnicity. For example, compared to the other groups, black-Africans were more likely to be younger. A higher proportion of black-Africans also attended university and were still in employment.

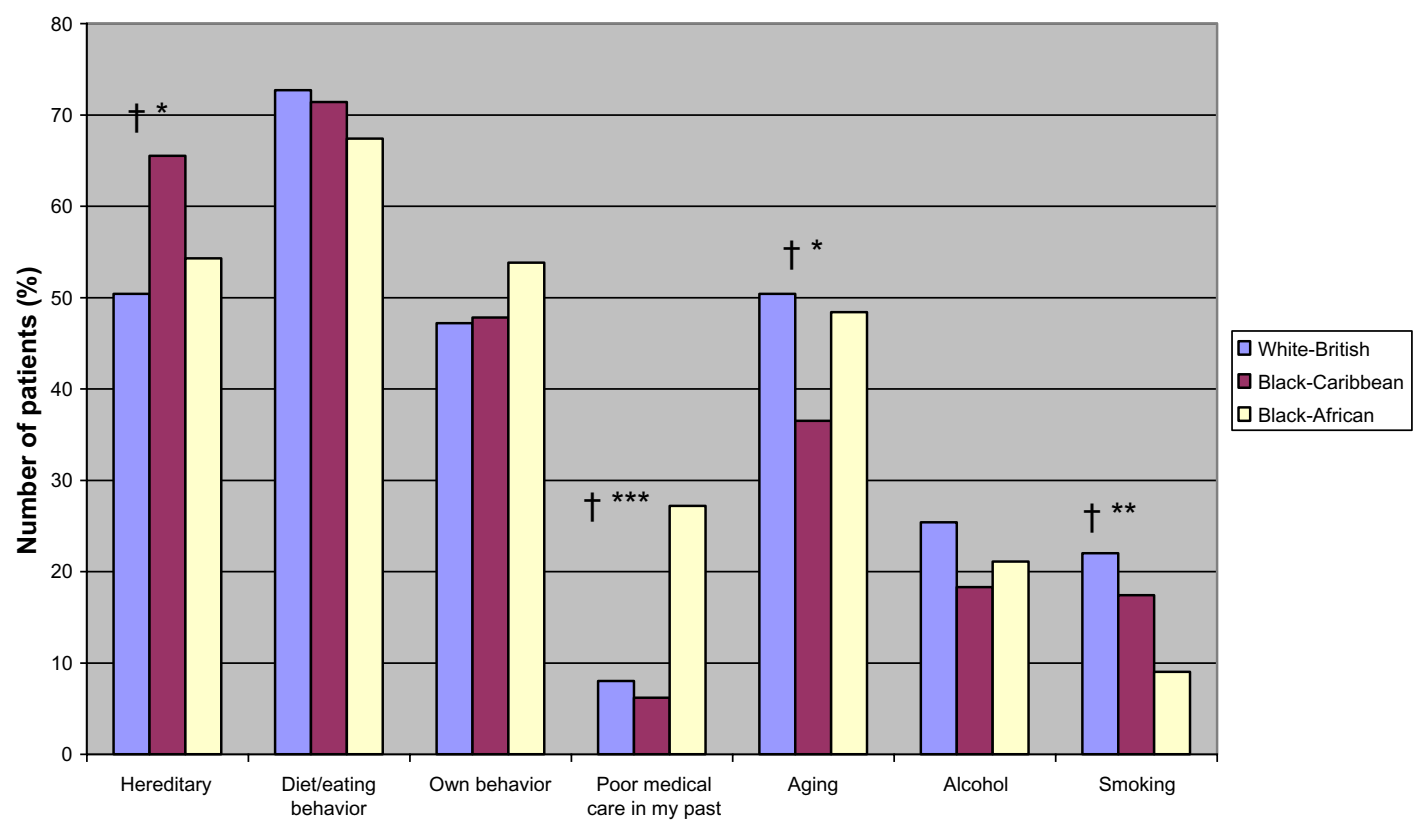

Figure 2 Perceived risk factor causes of diabetes by ethnicity.

Notes: †Significant linear trend; $* P \leq 0.03$; $* * P \leq 0.01$; $* * * P \leq 0.00$ I; for significant differences between ethnic groups ( $P$-values are from chi-square tests). 


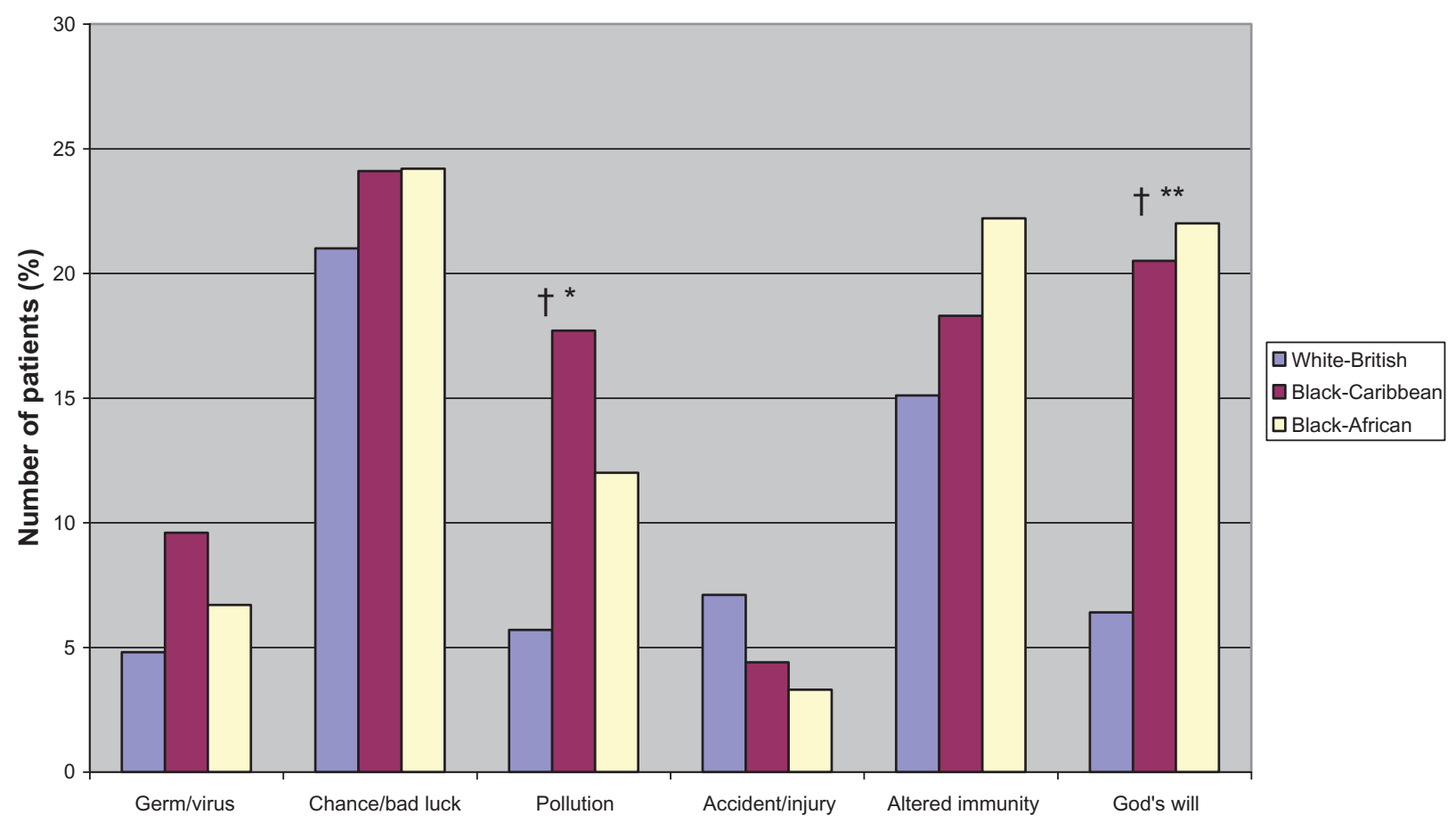

Figure 3 Perceived other causes of diabetes by ethnicity.

Notes: ‘Significant linear trend; $* P \leq 0.03$; $* * P \leq 0.0$ I; for significant differences between ethnic groups ( $P$-values are from chi-square tests).

Table I Demographic/disease characteristics of participants by self-reported ethnicity

\begin{tabular}{|c|c|c|c|}
\hline Descriptive & White-British $(\mathrm{N}=137)$ & Black-Caribbean $(\mathrm{N}=123)$ & Black-African $(\mathbf{N}=99)$ \\
\hline Mean age (SD) & $61.54(1.5)$ & $59.07(I 1.9)$ & $52.16(10.4)^{* * *}$ \\
\hline Female (\%) & $61(44.5)$ & $76(62.3)$ & $44(44.4)$ \\
\hline \multicolumn{4}{|c|}{ Number of years resident in UK (\%) } \\
\hline $1-10$ years & $\mathrm{I}(0.7)$ & $7(5.7)$ & $22(22.2)$ \\
\hline$>11$ years & $3(2.3)$ & $94(77.1)$ & $75(75.8)$ \\
\hline Born/lived all life in UK & $133(97.0)$ & $21(17.2)$ & $\mathrm{I}(\mathrm{I} .0)$ \\
\hline \multicolumn{4}{|l|}{ Marital status (\%) } \\
\hline Single, divorced/widowed & $79(58.9)$ & $86(70.5)$ & $40(4 I .3)$ \\
\hline Married/live with partner & $55(41.0)$ & $36(29.5)$ & $57(58.8)$ \\
\hline \multicolumn{4}{|l|}{ Educational status (\%) } \\
\hline Primary/secondary & $88(67.7)$ & $75(63.0)$ & $19(19.6)^{* * *}$ \\
\hline College/sixth form/polytechnic & $17(13.1)$ & $29(24.4)$ & $45(46.4)^{* * *}$ \\
\hline University/above & $25(19.2)$ & $15(12.6)$ & $33(34.0)^{* * *}$ \\
\hline \multicolumn{4}{|l|}{ Employment status (\%) } \\
\hline Employed (FT/PT) & $49(36.0)$ & $46(38.0)$ & $66(67.3)^{* * *}$ \\
\hline Unemployed/FT education & $23(16.9)$ & $24(20)$ & $20(20.4)$ \\
\hline Retired & $64(47.1)$ & $5 I(42.1)$ & $12(12.2)^{* * *}$ \\
\hline Percentage with $\mathrm{HbA}_{\mathrm{Ic}}>7.0$ & $57(50.9)$ & $64(65.3)$ & $59(67.8)^{*}$ \\
\hline Duration of diabetes & $8.36(7.7)$ & $9.71(8.0)$ & $6.10(5.3)^{* *}$ \\
\hline Mean BMI (SD) & $33.44(6.5)$ & $31.43(7.1)$ & $31.35(5.3)$ \\
\hline Hypertension & $56(44.1)$ & $77(67.5)$ & $59(60.8)^{* *}$ \\
\hline Family history of diabetes & $70(51.9)$ & $88(73.3)$ & $48(48.5)^{* *}$ \\
\hline Microvascular complication & $49(54.4)$ & $29(47.5)$ & $39(48.1)$ \\
\hline \multicolumn{4}{|l|}{ Type of treatment (\%) } \\
\hline Diet and exercise & $22(16.2)$ & $3(2.5)$ & $6(6.2)^{* *}$ \\
\hline Diabetic tablets & $79(58.1)$ & $80(66.1)$ & $64(66.0)$ \\
\hline Insulin & $35(25.7)$ & $38(31.4)$ & $27(27.8)$ \\
\hline
\end{tabular}

Note: $* P \leq 0.03 ; * * P \leq 0.01 ; * * * P \leq 0.001$.

Abbreviations: BMI, body mass index; FT, full-time; $\mathrm{HbA}_{\mathrm{lc}}$, glycated hemoglobin; PT, part-time; SD, standard deviation; vs, versus. 
The duration of diabetes was shorter in black-Africans but there was no difference in average body mass index between groups. Also, the proportions of participants on insulin and hypoglycemic agents were similar across ethnic groups. However, smaller proportions of black-African and black-Caribbean participants were on lifestyle only (diet and exercise) treatments.

\section{Ethnic differences in knowledge, illness perceptions, self-management, and metabolic control}

To ensure that ethnic differences in measured variables were not confounded by demographic/disease characteristics, correlation coefficients between the two sets of variables were first produced. Subsequent comparisons between ethnic groups then took into account demographic/disease characteristics that were found to significantly correlate with the measured variable of interest. Table 2 shows the mean scores for knowledge, illness perceptions, and DSM by ethnic group. White-British participants had higher diabetes knowledge scores compared to their black-African
(11\% point difference) and black-Caribbean (7\% point difference) counterparts. There was no statistically significant difference in diabetes knowledge between black-African and black-Caribbean participants.

The three ethnic groups also differed in their levels of adherence to DSM recommendations (Table 2B). Black-Africans had higher overall DSM scores compared to the other two groups. Black-Africans also reported higher adherence to dietary and exercise self-management recommendations compared to black-Caribbean patients and higher adherence to foot management compared to white-British patients. Generally, black-Caribbean participants had lower adherence scores for most aspects of DSM regimen, except foot management.

As seen in Table 2C, there were no ethnic differences in the perceptions of diabetes regarding symptom load (identity), patients' perceived control over diabetes (personal control), or their perception of the stability or otherwise (timelinecyclical) of diabetes. However, illness perceptions differed by ethnic groups in all other dimensions. Compared to whiteBritish, both black-Caribbean and black-Africans perceived diabetes as short term (timeline-acute/chronic) and benign

Table 2 Ethnic differences in diabetes-specific knowledge, illness perceptions, self-management, and metabolic control outcomes

\begin{tabular}{|c|c|c|c|c|}
\hline Characteristic & White-British & Black-Caribbean & Black-African & $P$-value \\
\hline (A) Percentage knowledge score $e^{a, e, t, y}(N=340)$ & $64.22(1.55)^{\mathrm{a}, \mathrm{c}}$ & $57.10(1.38)^{\mathrm{w}}$ & $53.41(1.55)^{\mathrm{w}}$ & $<0.001$ \\
\hline \multicolumn{5}{|l|}{ (B) Self-management } \\
\hline Overall self-mgt ${ }^{2, t}(N=35 \mathrm{I})$ & $3.92(0.10)^{\mathrm{a}}$ & $3.73(0.11)^{\mathrm{a}}$ & $4.58(0.12)^{\mathrm{w}, \mathrm{c}}$ & $<0.001$ \\
\hline Diet self-mgta $(\mathrm{N}=356)$ & $5.03(0.16)$ & $4.62(0.16)^{\mathrm{a}}$ & $5.44(0.19)^{c}$ & 0.001 \\
\hline Exercise $^{\mathrm{s}, \mathrm{d}, \mathrm{t}}(\mathrm{N}=343)$ & $3.66(0.19)$ & $3.21(0.21)^{\mathrm{a}}$ & $4.18(0.23)^{c}$ & $<0.01$ \\
\hline $\operatorname{SMBG}^{\mathrm{d}, \mathrm{t}}(\mathrm{N}=343)$ & $3.5 I(0.2 I)$ & $3.35(0.22)$ & $3.74(0.24)$ & 0.45 \\
\hline Foot self-mgt $(\mathrm{N}=359)$ & $4.18(0.18)^{\mathrm{a}}$ & $4.29(0.19)$ & $4.96(0.22)^{w}$ & 0.14 \\
\hline \multicolumn{5}{|l|}{ (C) Illness perceptions } \\
\hline Identity (mean rank) $(\mathrm{N}=359)$ & 168.64 & 184.67 & 189.92 & 0.24 \\
\hline Timeline acute/chronic $(\mathrm{N}=359)$ & $23.41(0.72)^{a, c}$ & $19.29(0.76)^{\mathrm{a}, \mathrm{w}}$ & $18.12(0.85)^{w, c}$ & $<0.001$ \\
\hline Consequences $^{\mathrm{a}, \mathrm{e}, \mathrm{t}}(\mathrm{N}=340)$ & $16.54(0.58)^{\mathrm{a}}$ & $15.12(0.60)^{\mathrm{a}}$ & | $3.04(0.7 \mid)^{w, c}$ & 0.001 \\
\hline Personal control $(\mathrm{N}=359)$ & $22.36(0.72)$ & $22.16(0.76)$ & $23.86(0.84)$ & 0.27 \\
\hline Treatment control $(\mathrm{N}=336)$ & $16.76(0.5 \mathrm{I})^{\mathrm{a}}$ & $16.38(0.54)^{\mathrm{a}}$ & $18.63(0.61)^{\mathrm{w}, c}$ & 0.019 \\
\hline IIIness coherence $(N=359)$ & $18.14(0.57)^{c}$ & $15.90(0.60)^{\mathrm{w}}$ & 16.72 & 0.021 \\
\hline Timeline cyclical ${ }^{2, t}(N=35 \mathrm{I})$ & $8.93(0.38)$ & $9.38(0.39)$ & $9.81(0.45)$ & 0.34 \\
\hline Emotional representation ${ }^{\text {t,e }}(\mathrm{N}=343)$ & $13.95(0.59)$ & $|2.5|(0.62)^{\mathrm{a}}$ & $15.25^{c}$ & 0.017 \\
\hline Illness Perception Score ${ }^{a, t}(N=35 \mathrm{I})$ & $97.35(1.84)^{a, c}$ & $90.86(1.92)^{\mathrm{w}}$ & $89.64^{w}$ & 0.013 \\
\hline \multicolumn{5}{|l|}{ Causal perceptions } \\
\hline Psychological & 11.20 & 11.95 & 11.81 & 0.42 \\
\hline Risk factors & 11.37 & 10.76 & 10.40 & 0.09 \\
\hline External factors & 6.39 & 6.94 & 6.44 & 0.23 \\
\hline \multicolumn{5}{|l|}{ (D) Metabolic control outcomes } \\
\hline $\mathrm{HbA}_{\mathrm{lc}}{ }^{\mathrm{a}, \mathrm{d}}(\mathrm{N}=227)$ & $8.04(0.18)$ & $8.15(0.19)$ & $8.33(0.21)$ & 0.59 \\
\hline Percentage with microvascular complications $(\mathrm{N}=232)$ & 54.4 & 47.5 & 48.1 & 0.62 \\
\hline
\end{tabular}

Notes: ${ }^{a}$ significantly different from black-Africans; 'significantly different from black-Caribbean; dadjusted for duration of diabetes; eadjusted for educational status; tadjusted for treatment category; ${ }^{w}$ significantly different from white-British; 'adjusted for age; yadjusted for number of years resident in the UK. Please note that demographic/clinical variables with significant between-group differences were adjusted in analysis of covariance. Adjustments were conducted if demographic/clinical variables were significantly associated with respective outcome variables (see details in statistical analysis in methods).

Abbreviations: $\mathrm{HbA}_{1 \mathrm{c}}$, glycated hemoglobin; mgt, management; SMBG, self-monitoring of blood glucose. 
(IPS). Compared to white-British and black-Caribbean participants, black-Africans perceived their diabetes to have lesser consequences and could be controlled effectively or even be cured by their treatment. As recommended by the developers of the IPQ-R, a principal component analysis on the causal items resulted in three subgroups: psychological, lifestyle, and other causal beliefs. As shown in Table 2, no ethnic differences were found for the three composite cause subscales. However, there were a number of differences in the proportions of people who attributed their diabetes to individual cause items as shown in Figures 1-3. Considering the psychological items, higher proportions of black-African and black-Caribbean participants perceived their diabetes to be caused by family problems or other emotional issues compared to their whiteBritish counterparts (Figure 1). Similar differences in causal attributions were also observed for pollution and 'God's will' in the other causal beliefs (Figure 3).

After controlling for the differences in age and duration of diabetes, white-British participants had $0.29 \%$ and $0.11 \%$ lower $\mathrm{HbA}_{1 \mathrm{c}}$ values compared to black-African and blackCaribbean participants, respectively. However, these differences were not statistically significant (Table 2D).

\section{Predicting knowledge, self-management, and $\mathrm{HbA}_{\mathrm{lc}}$ levels from demographic/ disease characteristics}

Various demographic/disease characteristics were associated with knowledge, IPS, self-management, or metabolic control ( $\mathrm{HbA}_{1 \mathrm{c}}$ levels and microvascular complication status) in the multiple regression analyses. As seen in Table 3, only educational status or treatment category predicted knowledge about diabetes in any of the three groups. Compared to participants with primary/secondary education, white-British and black-Caribbean participants with university education had significantly higher diabetes-specific knowledge scores. Also, white-British and black-Africans who were treated with oral hypoglycemic agents or with insulin had significantly higher diabetes-specific knowledge scores compared to those who were treated with lifestyle only (diet/exercise) treatments.

Regressions for predicting self-management from demographic/disease characteristics are shown in Table 4. Older age in white-British and black-Caribbean participants was generally associated with higher adherence to DSM recommendations. Compared to those treated with diet/exercise alone, white-British patients treated with insulin also reported higher adherence to overall DSM and SMBG recommendations. Among black-Caribbean participants, longer residence in the UK was associated with lower adherence to overall, exercise, and foot DSM recommendations. Black-African participants with primary/secondary education adhered highly to dietary recommendations compared to those with higher levels of educational status.

Table 5 shows the results for predicting $\mathrm{HbA}_{1 \mathrm{c}}$ levels from demographic/disease characteristics by ethnicity. In both white-British and black-Caribbean participants, being

Table 3 Regression coefficients for predicting knowledge from demographic/disease characteristics for people with type 2 diabetes

\begin{tabular}{|c|c|c|c|c|c|}
\hline Predictor variable & B (SE) & $95 \% \mathrm{Cl}$ & $P$-value & $\beta$ & Adjusted $R^{2}$ \\
\hline (A) White-British $(\mathrm{N}=126)$ & & & & & 0.18 \\
\hline Duration of diabetes & $0.20(0.24)$ & $-0.28,0.67$ & $0.4 \mathrm{I}$ & 0.08 & \\
\hline University vs primary/secondary & $13.74(3.64)$ & $6.53,20.94$ & $<0.00$ I & 0.32 & \\
\hline College/sixth form vs primary/secondary & $10.88(4.18)$ & $2.60,19.16$ & 0.01 & 0.22 & \\
\hline Insulin vs food and exercise & $12.69(5.28)$ & $2.24,23.13$ & 0.02 & 0.33 & \\
\hline Diabetic tablet vs food and exercise & $6.48(4.12)$ & $-1.68,14.64$ & 0.12 & 0.19 & \\
\hline (B) Black-Caribbean $(\mathrm{N}=1 \mid 3)$ & & & & & 0.15 \\
\hline Age & $-0.25(0.13)$ & $-0.50,0.00$ & 0.05 & -0.20 & \\
\hline Duration of diabetes & $-0.15(0.18)$ & $-0.5 \mathrm{I}, 0.20$ & 0.39 & -0.09 & \\
\hline Number of years lived in UK & $0.47(1.91)$ & $-3.31,4.26$ & 0.81 & 0.02 & \\
\hline College/sixth form vs primary/secondary & $8.55(3.48)$ & $\mathrm{I} .64,15.45$ & 0.02 & 0.24 & \\
\hline University vs primary/secondary & $7.89(4.08)$ & $-0.19,15.97$ & 0.06 & 0.18 & \\
\hline (C) Black-Africans $(\mathrm{N}=95)$ & & & & & 0.10 \\
\hline Age & $-0.23(0.15)$ & $-0.53,0.08$ & 0.14 & -0.16 & \\
\hline Duration of diabetes & $0.31(0.34)$ & $-0.37,1.00$ & 0.37 & 0.34 & \\
\hline College/sixth form vs primary/secondary & $5.40(3.83)$ & $-2.20,13.00$ & 0.16 & 0.19 & \\
\hline University vs primary/secondary & $6.12(3.97)$ & $-1.77,14.02$ & 0.13 & 0.20 & \\
\hline Tablet vs diet & $12.27(5.64)$ & $1.06,23.49$ & 0.03 & 0.42 & \\
\hline Insulin vs diet & $15.69(6.74)$ & $2.29,29.08$ & 0.02 & 0.50 & \\
\hline
\end{tabular}

Abbreviations: $\mathrm{B}$, regression co-efficient; $\mathrm{Cl}$, confidence interval; $\mathrm{SE}$, standard error; $\beta$, standardized regression co-efficient; vs, versus; $R^{2}$, proportion of variance explained by model. 
Table 4 Regression coefficients for predicting self-management from demographic/disease characteristics for people with type 2 diabetes

\begin{tabular}{|c|c|c|c|c|c|}
\hline Predictor variable & B (SE) & $95 \% \mathrm{Cl}$ & $P$-value & $\beta$ & Adjusted $R^{2}$ \\
\hline \multicolumn{6}{|l|}{ (A) White-British } \\
\hline Overall DSM $(\mathrm{N}=136)$ & & & & & 0.10 \\
\hline Age & $0.025(0.01)$ & $0.01,0.04$ & 0.001 & 0.28 & \\
\hline Tablet vs diet & $0.09(0.26)$ & $-0.42,0.60$ & 0.73 & 0.04 & \\
\hline Insulin vs diet & $0.65(0.29)$ & $0.08,1.23$ & 0.03 & 0.25 & \\
\hline $\operatorname{Diet}(N=136)$ & & & & & 0.03 \\
\hline Age & $0.03(0.01)$ & $0.00,0.05$ & 0.04 & 0.18 & \\
\hline Gender & $0.37(0.32)$ & $-0.27,1.00$ & 0.25 & 0.10 & \\
\hline Exercise $(N=|3|)$ & & & & & 0.02 \\
\hline Duration of diabetes & $-0.03(0.03)$ & $-0.10,0.03$ & 0.27 & -0.12 & \\
\hline Tablet vs diet & $-0.11(0.55)$ & $-1.21,0.99$ & 0.84 & -0.02 & \\
\hline Insulin vs diet & $-0.67(0.72)$ & $-2.09,0.76$ & 0.36 & 0.13 & \\
\hline SMBG $(N=129)$ & & & & & 0.21 \\
\hline Duration of diabetes & $-0.02(0.03)$ & $-0.08,0.05$ & 0.63 & -0.05 & \\
\hline Tablet vs diet & $0.19(0.55)$ & $-0.91,1.28$ & 0.74 & 0.04 & \\
\hline Insulin vs diet & $2.82(0.72)$ & $1.40,4.25$ & $<0.001$ & 0.49 & \\
\hline Marital status & $-0.7 \mathrm{I}(0.40)$ & $-1.50,0.07$ & 0.08 & -0.14 & \\
\hline \multicolumn{6}{|l|}{ (B) Black-Caribbean } \\
\hline Overall DSM $(N=|2|)$ & & & & & 0.11 \\
\hline Age & $0.02(0.01)$ & $0.01,0.04$ & 0.01 & 0.23 & \\
\hline Number of years lived in UK & $-0.37(0.16)$ & $-0.69,-0.05$ & 0.02 & -0.20 & \\
\hline Tablet vs food and exercise & $-0.8 \mathrm{I}(0.62)$ & $-2.04,0.42$ & 0.19 & -0.30 & \\
\hline Insulin vs food and exercise & $-0.38(0.64)$ & $-1.64,0.88$ & 0.55 & -0.14 & \\
\hline $\operatorname{Diet}(N=|2|)$ & & & & & 0.05 \\
\hline Age & $0.04(0.01)$ & $0.01,0.07$ & $<0.01$ & 0.26 & \\
\hline Gender & $0.00(0.33)$ & $-0.65,0.66$ & 0.99 & 0.00 & \\
\hline Exercise $(N=121)$ & & & & & 0.12 \\
\hline Age & $0.02(0.02)$ & $-0.02,0.05$ & 0.33 & 0.09 & \\
\hline Gender & $-1.06(0.39)$ & $-1.83,-0.28$ & 0.01 & -0.23 & \\
\hline Number of years lived in UK & $-0.69(0.27)$ & $-1.23,-0.15$ & 0.01 & -0.22 & \\
\hline Tablet vs diet & $v 1.56(1.06)$ & $-3.65,0.53$ & 0.14 & -0.34 & \\
\hline Insulin vs diet & $-2.11(1.08)$ & $-4.25,0.4 \mathrm{I}$ & 0.05 & -0.45 & \\
\hline SMBG $(N=116)$ & & & & & 0.24 \\
\hline Age & $0.02(0.02)$ & $-0.02,3.89$ & 0.42 & 0.07 & \\
\hline Gender & $0.91(0.44)$ & $0.04,1.78$ & 0.04 & 0.17 & \\
\hline Duration of diabetes & $0.03(0.03)$ & $-0.04,0.10$ & 0.37 & 0.09 & \\
\hline Tablet vs diet & $-0.08(1.33)$ & $-2.7 \mathrm{I}, 2.55$ & 0.95 & -0.02 & \\
\hline Insulin vs diet & $2.12(1.39)$ & $-0.63,4.87$ & 0.13 & 0.39 & \\
\hline \multicolumn{6}{|l|}{ (C) Black-Africans } \\
\hline $\operatorname{Diet}(N=96)$ & & & & & 0.05 \\
\hline Age & $0.02(0.02)$ & $-0.02,0.05$ & 0.30 & 0.11 & \\
\hline College/sixth form vs primary/secondary school & $-1.31(0.49)$ & $-2.28,-0.34$ & 0.01 & -0.36 & \\
\hline University vs primary/secondary school & $-1.15(0.52)$ & $-2.17,-0.13$ & 0.03 & -0.30 & \\
\hline SMBG $(N=96)$ & & & & & 0.08 \\
\hline Duration of diabetes & $0.01(1.06)$ & $-0.10,0.12$ & 0.88 & 0.02 & \\
\hline College/sixth form vs primary/secondary school & $0.22(0.67)$ & $-1.11,1.55$ & 0.74 & 0.04 & \\
\hline University vs primary/secondary school & $1.08(0.70)$ & $-0.31,2.46$ & 0.13 & 0.21 & \\
\hline Tablet vs diet & $0.86(0.98)$ & $-|.08,2.8|$ & 0.38 & 0.17 & \\
\hline Insulin vs diet & $2.26(1.15)$ & $-0.02,4.54$ & 0.05 & 0.41 & \\
\hline
\end{tabular}

Abbreviations: B, regression co-efficient; Cl, confidence interval; DSM, Diabetes Self-Management; SE, standard error; SMBG, self-monitoring of blood glucose; $\beta$, standardized regression co-efficient; vs, versus; $R^{2}$, proportion of variance explained by model. 
Table 5 Regression coefficients predicting $\mathrm{HbA}_{\mathrm{Ic}}$ from demographic and clinical characteristics for people with type 2 diabetes

\begin{tabular}{|c|c|c|c|c|c|}
\hline Predictor variable & B (SE) & $95 \% \mathrm{Cl}$ & $P$-value & $\beta$ & Adjusted $R^{2}$ \\
\hline \multicolumn{5}{|l|}{ (A) White-British ( $N=87)$} & \multirow[t]{5}{*}{0.12} \\
\hline Age & $-0.02(0.01)$ & $-0.05,0.01$ & 0.16 & -0.16 & \\
\hline Duration of diabetes & $0.01(0.03)$ & $-0.04,0.06$ & 0.72 & 0.05 & \\
\hline Tablet vs food and exercise & $0.98(0.48)$ & $0.02,1.94$ & 0.05 & 0.32 & \\
\hline Insulin vs food and exercise & $1.64(0.63)$ & $0.39,2,89$ & 0.01 & 0.48 & \\
\hline \multicolumn{5}{|l|}{ (B) Black-Caribbean ( $N=73)$} & \multirow[t]{8}{*}{0.31} \\
\hline Age & $-0.06(0.02)$ & $-0.09,-0.02$ & $<0.01$ & -0.39 & \\
\hline Gender & $-0.87(0.35)$ & $-1.56,-0.18$ & 0.01 & -0.25 & \\
\hline Duration of diabetes & $0.06(0.03)$ & $0.01,0.12$ & 0.03 & 0.30 & \\
\hline College/sixth form vs primary/secondary & $0.27(0.45)$ & $-0.62,1.16$ & 0.54 & 0.07 & \\
\hline University vs primary/secondary & $-0.06(0.49)$ & $-1.05,0.92$ & 0.90 & -0.01 & \\
\hline Tablet vs diet & I.33(0.84) & $-0.35,3.02$ & 0.12 & 0.39 & \\
\hline Insulin vs diet & $2.15(0.91)$ & $0.32,3.96$ & 0.02 & 0.60 & \\
\hline \multicolumn{6}{|c|}{ (C) No demographic or clinical characteristic significantly predicted $\mathrm{HbA}_{\mathrm{c}}$ in black-Africans } \\
\hline
\end{tabular}

Abbreviations: $\mathrm{B}$, regression co-efficient; $\mathrm{Cl}$, confidence interval; $\mathrm{HbA}_{\mathrm{Ic}}$, glycated hemoglobin; SE, standard error; $\beta$, standardized regression co-efficient; vs, versus; $R^{2}$, proportion of variance explained by model.

treated with insulin was associated with higher $\mathrm{HbA}_{1 \mathrm{c}}$ (poorer glycemic control). Older age and female gender were associated with lower $\mathrm{HbA}_{1 \mathrm{c}}$ levels (better glycemic control), whereas longer duration of diabetes was associated with higher $\mathrm{HbA}_{1 \mathrm{c}}$ levels (poorer glycemic control) among black-Caribbean participants.

\section{Predicting IPS from $\mathrm{HbA}_{\mathrm{Ic}}$ levels and microvascular complication status}

In white-British ( $\mathrm{B}=0.88,95 \% \mathrm{CI}:-1.96$ to $3.72, \beta=0.07$, $P=0.54)$, black-Caribbean $(\mathrm{B}=2.28,95 \% \mathrm{CI}:-0.31$ to 4.88 , $\beta=0.20, P=0.08)$, or black-Africans ( $\mathrm{B}=0.05,95 \% \mathrm{CI}$ : -0.02 to $0.11, \beta=0.18, P=0.14), \mathrm{HbA}_{1 \mathrm{c}}$ levels did not predict IPS. Also, microvascular complication of diabetes did not predict whether patients perceived their diabetes as benign or life threatening (IPS) in white-British $(\mathrm{B}=-1.05$, 95\% CI: -9.35 to $7.26, \beta=-0.03, P=0.80)$, black-Caribbean ( $\mathrm{B}=2.66,95 \% \mathrm{CI}:-7.39$ to $12.70, \beta=0.07, P=0.60$ ), or black-Africans ( $\mathrm{B}=0.08,95 \% \mathrm{CI}:-0.14$ to $0.31, \beta=0.08$, $P=0.45)$.

\section{Discussion}

\section{Summary and discussion of findings}

Patients' perceptions about illnesses, including diabetes, have been reported as key determinants in the way they adhere to treatment recommendations. ${ }^{28}$ Few studies have examined variations in illness perceptions and diabetes self-management in relation to ethnicity. ${ }^{24,29}$ Thus far, none of these studies have included participants of African ancestry with different experiences and history of migration. Exploring ethnic differences in illness perceptions can help explain differences in behaviors such as adherence to self-management, and by extension, variations in clinical outcomes such as metabolic control for diabetes. ${ }^{17}$ This study investigated ethnic differences in diabetes-specific knowledge, illness perceptions, adherence to DSM recommendations, as well as $\mathrm{HbA}_{1 \mathrm{c}}$ levels. The study also examined the extent to which any of the diabetes-related outcomes above are influenced by demographic/disease characteristics.

Our results indicate that important differences exist, in relation to the way black-Africans, black-Caribbean, and white-British populations with diabetes perceive their condition and their adherence to DSM recommendations. Both black-African and black-Caribbean participants had poorer diabetes-specific knowledge than their white-British counterparts. Black-Caribbean participants generally reported lower adherence to DSM recommendations. Compared to their white-British counterparts, both black-African and blackCaribbean participants perceived their diabetes as a shortterm and benign condition, with less serious consequences. The results also indicate that, despite some similarities, significant differences exist among the three ethnic groups in relation to which demographic/disease characteristics predict knowledge, self-management, or metabolic control outcomes. For example, age, duration of diabetes, and educational status significantly contributed to variations in $\mathrm{HbA}_{1 \mathrm{c}}$ levels among black-Caribbean participants, yet none of these factors predicted $\mathrm{HbA}_{1 \mathrm{c}}$ levels in white-British or black-Africans. The finding that longer duration of residence in the UK was associated with poorer adherence to DSM recommendations in the black-Caribbean participants is worrying and further research to ascertain the reasons for 
this could be useful for planning diabetes education services for black-Caribbean patients.

The lower levels of diabetes-specific knowledge among black-Caribbean and black-Africans was perhaps not surprising, given that several other studies have reported similar findings among minority ethnic populations, both in the UK and elsewhere. ${ }^{30,31}$ Irrespective of ethnicity, over $70 \%$ of the participants failed to identify correctly questions related to: low calorie containing foods as the best diet for people with diabetes; food items not suitable for treating hypoglycemia; and what time period $\mathrm{HbA}_{1 \mathrm{c}}$ reflects as a measure of diabetes control. These questions depict practical situations, which people with diabetes would be expected to face on a daily basis when fulfilling the self-management recommendations. ${ }^{6}$ For example, people with diabetes have to be conscious of the amount of calories they consume at any point in time. They are also required to consume calorie-rich diets, to avert imminent hypoglycemic attacks.

Intricately related to the knowledge deficit among black-Caribbean and black-Africans was their numerous misconceptions about diabetes (eg, perceiving diabetes as a short-term, curable condition, with less severe consequences). Similar misconceptions about diabetes have been reported in other indigenous or minority populations, including African-American patients. ${ }^{24,29,32}$ For instance, compared to European-origin patients, Tongans in New Zealand perceived their diabetes as acute. ${ }^{24}$ Shorter-term perceptions about diabetes have also been reported among Asian and Pacific Island patients compared to their Europeanorigin counterparts. ${ }^{29}$ Perceiving diabetes as a short-term condition is incompatible with the actual chronic nature of the condition. Secondly, the unrealistic expectation (belief) of a possible cure may result in disappointment, and its attendant psychological ramifications. Equally worrying is black-African and black-Caribbean patients' perceptions that diabetes has less severe consequences. In fact, diabetes is a serious condition with debilitating consequences, and patients need to recognize this fact and pursue preventive behaviors, to help reduce its complications. ${ }^{28}$ It is not clear how attributing diabetes to factors such as 'Gods will' may influence patients' self-management behaviors. However, research has shown that, patients who perceive their condition to be controlled by powerful others, are less likely to engage in health-related behaviors. ${ }^{33}$

Despite their low knowledge scores and numerous inconsistent beliefs about diabetes, black-Africans reported comparatively higher adherence to DSM recommendations. This finding may be explained by the fact that, although some knowledge may be required to facilitate DSM, knowledge is not the main determinant of patients' self-management behavior. ${ }^{34}$ It is also possible that black-Africans unintentionally overestimated their self-management performance levels due to their poor knowledge about diabetes and what is involved in its management. For instance, some items in the SDSCA questionnaire asked patients about healthy eating and high fat foods. Patients can respond appropriately to such questions only if they have good knowledge of the nutrient content of food items, and daily dietary requirements for the various food nutrients.

After adjusting for demographic/disease characteristics, there were no statistically significant differences in $\mathrm{HbA}_{1 \mathrm{c}}$ levels between ethnic groups. However, unequivocal evidence indicates that a percentage reduction in $\mathrm{HbA}_{1 \mathrm{c}}$ could result in significant decrease in all-cause and diabetes-related mortality, as well as substantial reductions in the risk of diabetes complications. ${ }^{35,36}$ Therefore, although statistically not significant, the $0.29 \%$ difference in $\mathrm{HbA}_{1 \mathrm{c}}$ between white-British and black-Africans in this study may be clinically important.

\section{Limitations}

This study has a number of limitations which should be considered when interpreting its findings. For example, recent evidence suggests that self-management is an inherently complex concept and how patients make 'sense' of it may actually differ from the perspectives of policy makers or health care practitioners. ${ }^{37}$ Indeed patients' interpretation of self-management may be a product of their personal experiences of the illness and their sociocultural background. This complexity of self-management has led to calls for a rather focused and contextualized interpretation of the concept. ${ }^{37}$ Secondly, our study did not collect information as to whether or not participants had received any formal diabetes education after diagnosis. Such information might have been useful for explaining the ethnic variations in diabetes-specific knowledge. Also, as a cross-sectional study, it is neither feasible to determine the direction of effect in the reported associations, nor draw firm causal inferences from the findings. For example, the finding that treatment with insulin was associated with higher adherence to self-management recommendations can be given different interpretations. One plausible explanation is that treatment regimen is often used as an index of severity for type 2 diabetes. ${ }^{38}$ Thus, patients who have their treatment regimens changed from diet/exercise or hypoglycemic agents to insulin are likely to perceive that their condition is worsening and consequently, adhere highly 
to self-management recommendations. Another methodological limitation of our study is the potential for selection bias, given that participants were non-randomly sampled from only two boroughs of London (Brent and Hackney). Thus the findings reported here are limited to the populations studied, although policy makers and practitioners working in similar populations may draw useful lessons from them. Finally, self-reported questionnaires were used in this study. It is therefore likely that some participants responded to the questions in ways that portray them as good or adherent to recommendations and not necessarily their 'true' behavior or perceptions (social desirability bias). It may be appropriate for future studies to further explore these issues using objective measures such as blood glucose monitors and pedometers as well as real-time data collection devices such as Personal Digital Assistants (PDAs).

\section{Conclusion}

Various demographic/disease characteristics were associated with knowledge, illness perceptions, and self-management in all ethnic groups. These characteristics should therefore be taken into consideration when assessing the needs of people with diabetes for possible intervention. Even after controlling for demographic/disease characteristics, there were still significant differences in knowledge, illness perceptions, and self-management of diabetes among the three ethnic groups. The two populations of African-origin (black-African and black-Caribbean) had substantially poor knowledge levels and high levels of misconceptions about their diabetes. Whilst we urgently call for future research to explore how the high knowledge deficit and misconceptions about diabetes in the African-origin populations impact on their self-management behaviors, it is also appropriate to highlight some important lessons to be drawn from our findings. Adequate and appropriate levels of disease-specific knowledge and perceptions are essential for individuals to accept diagnosis of a complex disease like diabetes and to facilitate their understanding of the required behavior changes needed to ensure optimum selfmanagement and improved disease outcomes. There is therefore the need for effective interventions aimed at addressing the knowledge misconception gap between African-origin and white-British populations with diabetes. The findings also present a number of lessons for health care professionals (HCPs), researchers, and policy makers. For example, the specific misconceptions (such as diabetes being a short-term and less serious condition) discovered in this study, present opportunities for HCPs and researchers to effectively work towards changing such negative and inconsistent beliefs among individuals and specific patient groups. ${ }^{39,40}$ Secondly, given the sub-optimal levels of adherence to DSM recommendations, particularly among black-Caribbean patients, HCPs may need to work collaboratively with individuals and groups of patients to identify barriers preventing them from engaging in self-management, and work towards resolving such barriers. Finally, important knowledge deficits were also found in all patient groups, particularly on areas bordering on practicalities of DSM, indicating the need for HCPs to emphasize practical and skill-based aspects of DSM during self-management education, and to periodically review and supplement the knowledge requirements of all patients.

\section{Disclosure}

This study was funded by a grant from the Alliance for Self Care Research consortium. The authors report no conflicts of interest in this work.

\section{References}

1. International Diabetes Federation. IDF Diabetes Atlas Update 2012 Brussels: International Diabetes Federation; 2012. Available from: http:// www.idf.org/diabetesatlas/5e/Update2012. Accessed May 2, 2013.

2. Ekoé JM, Zimmet P. Diabetes Mellitus: diagnosis and classification. In: Ekoé JM, Zimmet P, Williams R, editors. The Epidemiology of Diabetes Mellitus: an International Perspective. Chichester: John Wiley; 2001:11-29.

3. American Diabetes Association. Economic costs of diabetes in the U.S in 2007. Diabetes Care. 2008;31:596-615.

4. Diabetes UK. Diabetes Heartache: The Hard Reality of Cardiovascular Care for People with Diabetes. 2007, London: Diabetes UK; 2007. Available from: http://www.diabetes.org.uk/Documents/News/ Heartache_report07.pdf. Accessed June 13, 2013.

5. Rijken M, Jones M, Heijmans M, Dixon A. Supporting Self-management. In: Nolte E, McKee M, editors. Caring for People with Chronic Conditions: A Health System Perspective. Maidenhead: Open University Press; 2008:116-142.

6. American Diabetes Association. Standards of medical care in diabetes - 2008. Diabetes Care. 2008;31:S12-S54.

7. Manderson L, Kokanovic R. "Worried all the time": distress and the circumstances of everyday life among immigrant Australians with type 2 Diabetes. Chronic Illn. 2009;5:21-32.

8. Agyemang C, Bhopal R, Bruijnzeels M. Negro, Black, Black African, African Caribbean, African American or what? Labelling African origin populations in the health arena in the 21 st century. $J$ Epidemiol Community Health. 2005;59:1014-1018.

9. Saleh A, Amanatidis S, Samman S. Cross-sectional study of diet and risk factors for metabolic diseases in a Ghanaian population in Sydney, Australia. Asia Pac J Clin Nutr. 2002;11:210-216.

10. UK Department of Health. Health Survey for England 2004: The Health of Minority Ethnic Groups. London; UK Department of Health; 2005.

11. Ong KL, Cheung BM, Wong LY, Wat NM, Tan KC, Lam KS Prevalence, treatment, and control of diagnosed diabetes in the U.S National Health and Nutrition Examination Survey 1999-2004. Ann Epidemiol. 2008;18:222-229.

12. Baskar V, Kamalakannan D, Holland MR, Singh BM. Does ethnic origin have an independent impact on hypertension and diabetic complications? Diabetes Obes Metabol. 2006;8:214-219.

13. Lambie M, Richards N, Smith S. Ethnicity, age and incidence rates for renal replacement therapy (RRT) in Birmingham, UK: 1990-2004. Nephrol Dial Transplant. 2008;23:3983-3987. 
14. Kirk JK, Agostino RB, Bell RA, et al. Disparities in $\mathrm{HbA}_{1 \mathrm{c}}$ Levels between African-American and non-Hispanic white adults with diabetes. Diabetes Care. 2006;29:2130-2136.

15. Adams AS, Trinacty CM, Zhang F, et al. Medication adherence and racial differences in $\mathrm{A}_{1 \mathrm{c}}$ control. Diabetes Care. 2008;31:916-921.

16. Griva K, Myers LB, Newman S. Illness perceptions and self efficacy beliefs in adolescents and young adults with insulin dependent diabetes mellitus. Psychol Health. 2000;15:733-750.

17. Nwasuruba C, Khan M, Egede L. Racial/ethnic differences in multiple self-care behaviors in adults with diabetes. J Gen Intern Med. 2007;22: 115-120.

18. Office for National Statistics. Census 2001 Key Statistics, Local Authorities in England and Wales. Newport: Office for National Statistics; 2001. Available from http://www.ons.gov.uk/ons/rel/census/census-2001-keystatistics/local-authorities-in-england-and-wales/index.html. Accessed on June 25, 2013.

19. Abubakari AR, Jones MC, Lauder W, Kirk A, Anderson J, Devendra D. Associations between knowledge, illness perceptions, self-management and metabolic control of type 2 diabetes among African and Europeanorigin patients. J Nurs Healthc Chronic Illn. 2011;3:245-256.

20. Fitzgerald JT, Funnell MM, Hess GE, et al. The reliability and validity of a brief diabetes knowledge test. Diabetes Care. 1998;21:706-710.

21. Toobert DJ, Hampson SE, Glasgow RE. The summary of diabetes self-care activities measure: results from 7 studies and a revised scale. Diabetes Care. 2000;23:943-950.

22. Moss-Morris R, Weinman J, Petrie K, Horne R, Cameron L, Buick D. The Revised Illness Perception Questionnaire (IPQ-R). Psychol Health. 2002;17:1-16.

23. Abubakari AR, Jones MC, Lauder W, Kirk A, Devendra D, Anderson J. Psychometric properties of the Revised Illness Perception Questionnaire: Factor structure and reliability among African-origin populations with type 2 diabetes. Int J Nurs Stud. 2011;49:672-681.

24. Barnes, L, Moss-Morris R, Kaufusi M. Illness beliefs and adherence in diabetes mellitus: a comparison between Tongan and European patients. N Z Med J. 2004;117(1188):U743.

25. Koffman J, Morgan M, Edmonds P, Speck P, Higginson IJ. "I know he controls cancer": the meanings of religion among Black Caribbean and White British patients with advanced cancer. Soc Sci Med. 2008;67:780-789.

26. Broadbent E, Petrie KJ, Main J, Weinman J. The brief illness perception questionnaire. J Psychosom Res. 2006;60:631-637.
27. Tabachnick BG, Fidell LS. Using Multivariate Statistics. 3rd ed. New York: HarperCollins College; 1996.

28. Glasgow RE, Hampson SE, Strycker LA, Ruggiero L. Personal-model beliefs and social-environmental barriers related to diabetes selfmanagement. Diabetes Care. 1997;20:556-561.

29. Bean D, Cundy T, Petrie KJ. Ethnic differences in illness perceptions, selfefficacy and diabetes self-care. Psychol Health. 2007;22:787-811.

30. Baradaran H, Knill-Jones R. Assessing the knowledge, attitudes and understanding of type 2 diabetes amongst ethnic groups in Glasgow, Scotland. Pract Diabetes Int. 2004;21:143-148.

31. Persell SD, Keating NL, Landrum MB, et al. Relationship of diabetesspecific knowledge to self-management activities, ambulatory preventive care, and metabolic outcomes. Prev Med. 2004;39:746-752.

32. Mann DM, Ponieman D, Leventhal H, Halm EA. Misconceptions about diabetes and its management among low-income minorities with diabetes. Diabetes Care. 2009;32:591-593.

33. Wallston KA. The validity of the multidimensional health locus of control scales. J Health Psychol. 2005;10:623-631.

34. Nuovo J. Type 2 diabetes. In: Nuovo J, editor. Chronic Disease Management. New York: Springer; 2007:139-187.

35. Stratton IM, Adler AI, Neil HA, et al. Association of glycaemia with macrovascular and microvascular complications of type 2 diabetes (UKPDS 35): prospective observational study. BMJ. 2000;321: 405-412.

36. Ray KK, Seshasai SR, Wijesuriya S, et al. Effect of intensive control of glucose on cardiovascular outcomes and death in patients with diabetes mellitus: a meta-analysis of randomised controlled trials. Lancet. 2009;73:1765-1772.

37. Atkin K, Stapley S, Easton A. No one listens to me, nobody believes me: self management and the experience of living with encephalitis. Soc Sci Med. 2010;71:386-393.

38. Lemp GF, Zwaag RV, Hughes JP, et al. Association between the severity of diabetes mellitus and coronary arterial atherosclerosis. Am J Cardiol. 1987;60:1015-1059.

39. Petrie KJ, Cameron LD, Ellis CJ, Buick D, Weinman J. Changing illness perceptions after myocardial infarction: an early intervention randomized controlled trial. Psychosom Med. 2002;64:580-586.

40. Keogh KM, White P, Smith SM, McGilloway S, O’Dowd T, Gibney J. Changing illness perceptions in patients with poorly controlled type 2 diabetes, a randomised controlled trial of a family-based intervention: protocol and pilot study. BMC Fam Pract. 2007;8:36.
International Journal of General Medicine

\section{Publish your work in this journal}

The International Journal of General Medicine is an international, peer-reviewed open-access journal that focuses on general and internal medicine, pathogenesis, epidemiology, diagnosis, monitoring and treatment protocols. The journal is characterized by the rapid reporting of reviews, original research and clinical studies across all disease areas.

\section{Dovepress}

A key focus is the elucidation of disease processes and management protocols resulting in improved outcomes for the patient.The manuscript management system is completely online and includes a very quick and fair peer-review system. Visit http://www.dovepress.com/ testimonials.php to read real quotes from published authors. 